\title{
Fractal analysis of polyferric chloride-humic acid (PFC-HA) flocs in different topological spaces
}

\author{
WANG Yili ${ }^{1, *}$, LU Jia $^{1}$, DU Baiyu ${ }^{1}$, SHI Baoyou ${ }^{2}$, WANG Dongsheng ${ }^{2}$ \\ 1. College of Environmental Science and Engineering, The Key Laboratory for Silviculture and Conservation of Ministry of Education, Beijing Forestry \\ University, Beijing 100083, China. E-mail: wangyilimail@126.com \\ 2. State Key Laboratory of Environmental Aquatic Chemistry, Research Center for Eco-Environmental Sciences, \\ Chinese Academy of Sciences, Beijing 100085, China
}

\begin{abstract}
The fractal dimensions in different topological spaces of polyferric chloride-humic acid (PFC-HA) flocs, formed in flocculating different kinds of humic acids (HA) water at different initial $\mathrm{pH}(9.0,7.0,5.0)$ and $\mathrm{PFC}$ dosages, were calculated by effective densitymaximum diameter, image analysis, and $\mathrm{N}_{2}$ absorption-desorption methods, respectively. The mass fractal dimensions $\left(D_{\mathrm{f}}\right)$ of PFC-HA flocs were calculated by bi-logarithm relation of effective density with maximum diameter and Logan empirical equation. The $D_{\mathrm{f}}$ value was more than 2.0 at initial $\mathrm{pH}$ of 7.0, which was $11 \%$ and $13 \%$ higher than those at $\mathrm{pH} 9.0$ and 5.0, respecively, indicating the most compact flocs formed in flocculated HA water at initial $\mathrm{pH}$ of 7.0. The image analysis for those flocs indicates that after flocculating the HA water at initial $\mathrm{pH}$ greater than 7.0 with PFC flocculant, the fractal dimensions of $D_{2}\left(\log A\right.$ vs. $\left.\log d_{\mathrm{L}}\right)$ and $D_{3}\left(\log V_{\text {sphere }}\right.$ vs. $\log d_{\mathrm{L}}$ ) of PFC-HA flocs decreased with the increase of PFC dosages, and PFC-HA flocs showed a gradually looser structure. At the optimum dosage of PFC, the $D_{2}\left(\log A\right.$ vs. $\left.\log d_{\mathrm{L}}\right)$ values of the flocs show $14 \%-43 \%$ difference with their corresponding $D_{\mathrm{f}}$, and they even had different tendency with the change of initial $\mathrm{pH}$ values. However, the $D_{2}$ values of the flocs formed at three different initial $\mathrm{pH}$ in HA solution had a same tendency with the corresponding $D_{\mathrm{f}}$. Based on fractal Frenkel-Halsey-Hill (FHH) adsorption and desorption equations, the pore surface fractal dimensions $\left(D_{\mathrm{s}}\right)$ for dried powders of PFC-HA flocs formed in HA water with initial $\mathrm{pH} 9.0$ and 7.0 were all close to 2.9421 , and the $D_{\mathrm{s}}$ values of flocs formed at initial $\mathrm{pH} 5.0$ were less than 2.3746 . It indicated that the pore surface fractal dimensions of PFC-HA flocs dried powder mainly show the irregularity from the mesopore-size distribution and marcopore-size distribution.
\end{abstract}

Key words: polyferric chloride-humic acid (PFC-HA) flocs; topological spaces; fractal dimensions; effective density; image analysis; pore surface fractal

\section{Introduction}

Humic acids (HAs) are one of the main constituents of natural organic matter (NOM) in surface waters (Edzwald, 1993; Edzwald and Tobiason, 1999; Jekel, 1986). It has been recognized that NOM is the primary precursor of many important disinfection byproducts (DBPs) formed during water chlorination. DBPs, such as trihalomathanes (THMs), haloacetic acids (HAAs), are suspected carcinogens, which pose great health risks to water consumers (Edzwald, 1993; Edzwald and Tobiason, 1999; Jekel, 1986). The United States Environmental Protection Agency has proposed that enhanced coagulation is a best available technology (BAT) for NOM removal. Extensive previous studies have paid the most attention to the reaction behavior between $\mathrm{FeCl}_{3}$ and HAs (Edzwald, 1993; Edzwald and Tobiason, 1999; Jacangelo et al., 1995). The results proved that $\mathrm{FeCl}_{3}$ had good performance on HAs removal during enhanced coagulation process. However, a few studies focused on the HAs removal and coagulated

\footnotetext{
* Corresponding author. E-mail: wangyilimail@126.com
}

flocs with polyferric chloride (PFC), an inorganic polymer flocculant (IPF), which had a good performance on particle removal from natural water or wastewater. These research works show that PFC has good performance on HAs removal (Wang et al., 2006a, 2006b), and the formed PFC-HAs flocs with fractal morphology have an important effect on HAs removal also.

A review of previous work shows floc fractal properties, such as mass fractal or fractal characteristics under different dimensions, could give some hints on the formation dynamics and the microstructure of flocs induced by coagulants. Generally, a mass fractal may have some influence on bulk physical structural characteristics, such as floc density, settling rates, and floc strength (Gregory, 1997; Li and Logan, 2001; Serra and Logan, 1999). A twodimensional fractal dimension could indicate the compact or loose structure of flocs, and floc irregular boundary could have positive relation with the one-dimensional fractal characteristics (Feder, 1988; Gregory, 1997; Jiang and Logan, 1991; Li and Logan, 2001; Mandelbrot, 1982; Serra and Logan, 1999). In fact, the physical and chemical 
properties of floc surface also have an important effect on the kinetic growing of flocs, and more irregular and rough surfaces will imply high collision and attachment rates between different flocs in flocculation/flotation and filtration ect. However, the surface fractal dimension as an indication on the irregularity and roughness of surfaces (Avnir et al., 1983, 1985; Douglas, 1989; Fripiat et al., 1986; Neimark and Unger, 1993; Pfeifer and Obert, 1989; Pfeifer et al., 1989; Russ, 1994; Wang, 2006b, 2007) has rarely been reported in above coagulation process.

In this article, the fractal dimensions of polyferric chloride humic acid (PFC-HA) flocs in different topological spaces were studied.

\section{Materials and methods}

\subsection{Humic acid solutions}

Solutions of test water were prepared using dissolved HAs reagent (Tianjin Jinke Fine Chemical Institute, China) in deionized water and filtrated with a $0.45-\mu \mathrm{m}$ membrane, then diluted with tap water of equal volume, corresponding to a mass concentration $4.79 \mathrm{mg} / \mathrm{L}$ (as dissolved organic carbon (DOC)) and $0.33 \mathrm{~cm}^{-1}$ for UV absorbance at 254 $\mathrm{nm}\left(\mathrm{UV}_{254}\right)$ was performed. A $1000-\mathrm{mL}$ solution sample was used in the coagulation jar test. The initial $\mathrm{pH}$ of this solutions were kept at $9.00 \pm 0.05,7.00 \pm 0.05$, $5.00 \pm 0.05$, respectively. Moreover, the turbidity of these solutions was close to 1.12 NTU (Turbidimeter $2100 \mathrm{~N}$, HACH, USA).

\subsection{Coagulant}

Polyferric chloride (Tianjin Tianshui Water Purifying Ltd., China) was used as coagulant. PFC, with basicity (OH/Al molar percentage) $15.4 \%$, contained $10.4 \%(\mathrm{~W} / \mathrm{W})$ $\mathrm{Fe}_{2} \mathrm{O}_{3}$ and was diluted to $0.1761 \mathrm{~mol} / \mathrm{L}$ solution with ultrapurified water for use.

\subsection{Apparatus and procedures}

\subsubsection{Jar test}

Coagulation experiments were carried out by performing a series of jar tests. A JTY variable-speed jar tester (Tangshan Dachang Chemical Ltd., China) was used with $50 \mathrm{~mm} \times 40 \mathrm{~mm}$ flat paddle impellers with cylindrical jars containing $1 \mathrm{~L}$ sample. Two speeds were used with a rapid mix at $200 \mathrm{r} / \mathrm{min}$ for $1.0 \mathrm{~min}$, followed by a slow stir phase at $30 \mathrm{r} / \mathrm{min}$ for $15 \mathrm{~min}$. Then, the flocs were allowed to settle for $30 \mathrm{~min}$, after measurements of $\mathrm{UV}_{254}$, turbidity measurements were taken. A 50-mL supernatant collected from just below the water surface was analyzed for $\mathrm{UV}_{254}$ using a UV-Vis spectrum meter (UV8500, Shanghai Techcomp Ltd., China), and turbidity was measured at the same time. In addition, the $\mathrm{pH}$ of supernatant was measured. During this stage, $\mathrm{UV}_{254}$ removal was used as an indicator of NOM removal. Three kinds of flocs were produced at every optimum coagulant dosage. When initial $\mathrm{pH}$ was 9.0, 7.0, and 5.0, the corresponding optimum PFC dosages were $22.93,14.20$, and $14.20 \mathrm{mg} / \mathrm{L}$ (as $\mathrm{Fe}^{3+}$ ), respectively, for HA solution.

\subsubsection{Floc settling rate and fractal dimension}

The experimental apparatus for the settling of flocs consists of a Pyrex glass column (Fig. 1). The column is $400 \mathrm{~mm}$ in height to ensure that the terminal settling velocity could be reached, and $30 \mathrm{~mm}$ in radius was set to neglect the wall effect on aggregate settling. During each run of the settling-coagulation experiments, a floc was introduced into the top of the column, which was filled with deionized water. After the slow mixing, flocs were withdrawn from the stirred tank. To ensure that the free water within the flocs was exactly the same in density as that in the setting column, prior to being introduced into the settling column, the flocs were transferred in series through two Petri dishes of water identical to that used for making solution placed in the column using a wide mouthed pipet. Flocs that broke up during any transfer steps were discarded.

Images of floc, while passing through the observation region in the Pyrex glass-settling column, were captured using a microscope objective (AVENIR TV Zoom Lens SR12575, 12.5 mm-75 mm F1.8, Japan) connected with a HV1302UM charge-coupled device (CCD) camera (China Daheng Group Corporation, Beijing Image Vision Technology Branch) and a computer. Image analysis software (MiVnt, China Daheng Group Corporation, Beijing Image Vision Technology Branch) was used to determine the floc settling velocity and had been calibrated using a yardstick. The image grabber was manually triggered to take a series of 20 images. The time between each frame was set at $1 \mathrm{~s}$. This indicates that the distance traveled by the floc could be calculated per frame and therefore per time period, thus giving a settling velocity. The equivalent diameter of each floc was recorded with another HV1302UM chargecoupled device (CCD) camera after it settles to the bottom of this column and had been calibrated using a coin for approximately 120 aggregates for each set of coagulation conditions.

\subsubsection{Floc image acquisition and processing}

To obtain the floc images with high resolution, a image processing system (Fig. 2) was built, and its main components include a computer-controlled digital CCD camera (China Daheng Group Corporation, Beijing Image Vision Technology Branch), Computar Macro Zoom lens (MLM-

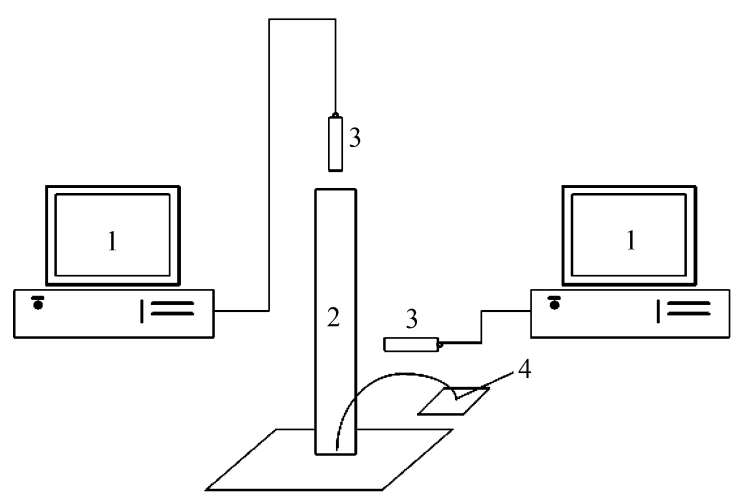

Fig. 1 Testing diagram for floc setting rate. (1) computer; (2) setting column; (3) charge-coupled device (CCD) camera; (4) flocs. 


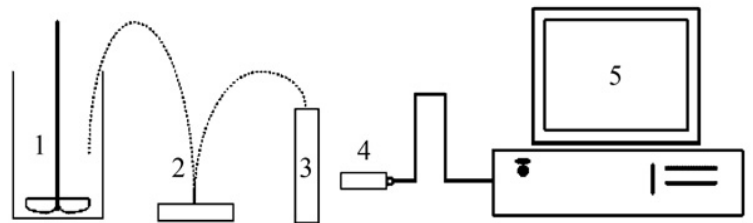

Fig. 2 Schematic methodology for floc images recording. (1) flocculation mixer; (2) petri dish; (3) colorimetric tube; (4) CCD; (5) computer

3XMP, Goyo Optical Inc., Japan), lighting provided by a stroboscopic lamp, image acquisition, and image analysis software. The strobe light was placed on the opposite side of the jar from the camera to provide back-lighting, which produces particle images as shadows. As a focused floc was introduced into a colorimetric tube filled with deionized water and passed through the observation region in the colorimetric tube, its images were recorded by computer-controlled digital CCD camera.

\subsubsection{Fractal geometry in different topological space}

Geometric characteristics were derived for the images collected after slow-stirring stage at optimum dosage of coagulant. Unlike spherical particles that can be described by a single parameter of diameter only, nonspherical particles can be characterized in many ways. The software then determines the area, the perimeter, and the secondorder moments of the image for each floc.

The effective density of floc can be deduced from its setting rate, and the mass fractal dimension can be calculated by regression analysis of the logarithm of the effective density versus the logarithm of the characteristic length, such as the diameter of equivalent circle and long axis of the particle image (Gregory, 1997; Wang and Tambo, 2000). When Reynolds numbers of a setting floc were between 0.1 and 1.0, the Logan empirical formula ( $\mathrm{Li}$ and Logan, 2001; Serra and Logan, 1999) was used to calculate the fluid drag coefficient $\left(C_{\mathrm{D}}\right)$. At other large Reynolds numbers, Allen or Logan empirical formulas (Yan and Fan, 1999) could be used to estimate $C_{\mathrm{D}}$. If $C_{\mathrm{D}}$ was determined, the effective density of a floc could be given through its relation with the setting rate.

The one-dimensional fractal dimension of flocs was calculated by regression analysis of the logarithm of their perimeter versus the logarithm of their corresponding characteristic length. The two-dimensional fractal dimension of flocs was calculated by regression analysis of the logarithm of their projected area versus the logarithm of their corresponding characteristic length or perimeter (Jin and Wang, 2001). In this work, the long diameter of the particle image was taken as the characteristic length. The threedimensional fractal dimension of flocs cannot be calculated in a similar manner as $D_{2}$ since aggregate volume cannot be measured directly with the present apparatus. However, aggregate volume can be estimated by assuming thickness in the direction normal to the viewing direction. Thus, the equivalent spheres and ellipsoid were used to estimate floc volume. Once their volumes were calculated, $D_{3}$ could obtained from regression analysis of these volumes versus their corresponding characteristic length similar to the procedure for $D_{2}$ (Jin and Wang, 2001). This method of calculating $D_{3}$ essentially represents a hypothesis that information on three dimensional characteristics can be extracted from a two-dimensional image.

\subsubsection{Cryofixation and vacuum drying of PFC-HA flocs}

Cryofixation of PFC-HA flocs samples were carried out by plunge freezing in liquid nitrogen at $77 \mathrm{~K}$. A $15-\mathrm{mL}$ plastic centrifugal tube containing $10 \mathrm{~mL}$ flocculated water with flocs was plunged in liquid-nitrogen tank for $30 \mathrm{~min}$. The cryofixation samples were put in the vacuum-freeze dryer (FD-1A, Beijing Boyikang Laboratory Instruments Ltd., China) for 24-48 h. Sublimation of the ice formed from void or interstitial water of the sample was then obtained by the vacuum-freeze drying process (Nègre et al., 2004). Then, the dry floc samples were obtained and stored in a desiccator.

\subsubsection{Analytical methods}

The surface area and pore size distribution of the dried PFC-HA powder have been measured by nitrogen adsorption using ASAP 2000 (Micromeritics, USA).

\subsubsection{Pore surface dimension}

To evaluate the pore surface fractal dimension of PFC$\mathrm{HA}$, flocs have been performed using a well-established method based on the fractal version of the Frenkel-HalseyHill (FHH) equation and thermodynamic equation. The length scale, where fractal behavior was determined from fractal FHH equation plots, was also computed according to the references (El Shafei et al., 2004; Neimark and Unger, 1993; Wang et al., 2006b, 2007).

\section{Results}

\subsection{Fractal dimensions in three-dimension topological space-mass fractal dimension}

Figure 3 shows the regression plot of the logarithm of the effective density $\left(\rho_{\mathrm{e}}\right)$ of the flocs at initial $\mathrm{pH}$ 7.00 versus the diameter of equivalent circle $\left(d_{\mathrm{P}}\right)$ or long diameter of their images $\left(d_{\mathrm{L}}\right)$. The effective densities were given when using Logan empirical equations for fluid drag coefficient $\left(C_{\mathrm{D}}\right)$ calculation. Then, according to Eq. (1), the mass fractal dimension $\left(D_{\mathrm{f}}\right)$ can be calculated from the slope of the regression lines.

$\rho_{\mathrm{e}} \propto d_{\mathrm{a}}^{D_{\mathrm{f}}-3}$

where, $\rho_{\mathrm{e}}$ is the effective density of floc and $d_{\mathrm{a}}$ is the diameter of equivalent circle or long diameter of floc. The regression plots for flocs at initial $\mathrm{pH} 9.0$ and 5.0 had the similar shape to that at initial $\mathrm{pH} 7.0$ and were omitted. The mass fractal dimensions of flocs at these three situations were given in Table 1 . It is easily observed that the correlation coefficient $(r)$ of linear regression of the logarithm of the effective density of flocs calculated by Logan empirical formulas versus long diameter of their images was higher than others. Therefore, the mass fractal dimensions can be calculated by the logarithm of the effective density of flocs calculated by Logan empirical formulas versus long diameter of their images. The mass 

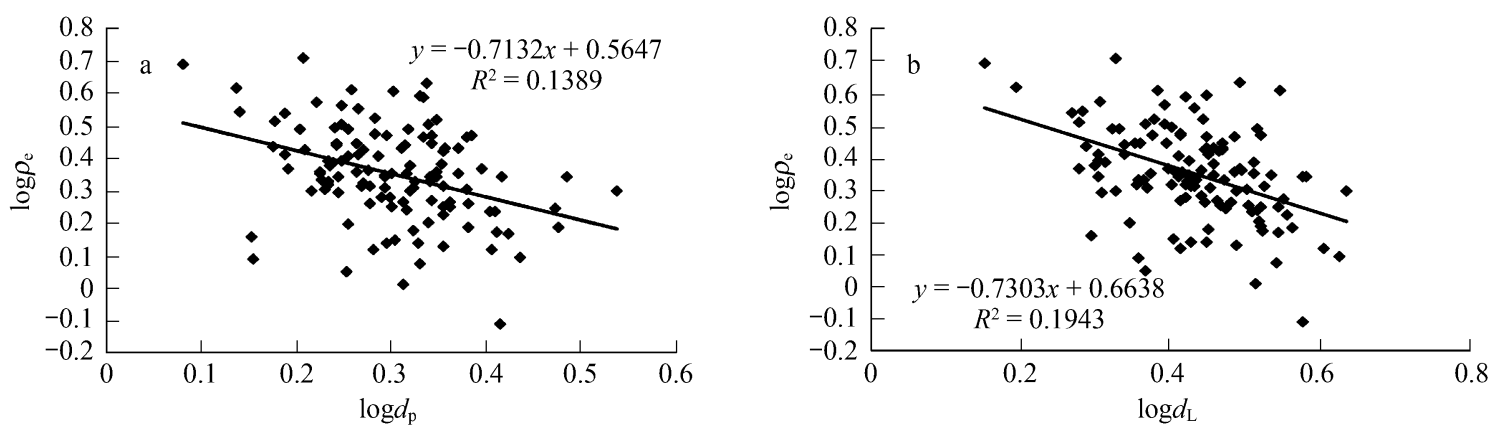

Fig. $3 \log \rho_{\mathrm{e}}$ vs. $\log d_{\mathrm{p}}$ (a) and $\log \rho_{\mathrm{e}}$ vs. $\log d_{\mathrm{L}}$ (b) plots for polyferric chloride-humic acid (PFC-HA) flocs.

Table 1 Mass fractal dimensions $\left(D_{\mathrm{f}}\right)$ of PFC-HA flocs with numbers of about 110-120

\begin{tabular}{|c|c|c|c|c|c|c|c|c|}
\hline \multirow[t]{2}{*}{ Initial $\mathrm{pH}$} & \multicolumn{2}{|c|}{$\left(\log \rho_{\mathrm{e}} \text { vs. } \log d_{\mathrm{p}}\right)^{\mathrm{a}}$} & \multicolumn{2}{|c|}{$\left(\log \rho_{\mathrm{e}} \text { vs. } \log d_{\mathrm{L}}\right)^{\mathrm{a}}$} & \multicolumn{2}{|c|}{$\left(\log \rho_{\mathrm{e}} \text { vs. } \log d_{\mathrm{p}}\right)^{\mathrm{b}}$} & \multicolumn{2}{|c|}{$\left(\log \rho_{\mathrm{e}} \text { vs. } \log d_{\mathrm{L}}\right)^{\mathrm{b}}$} \\
\hline & $D_{\mathrm{f}}$ & $r$ & $D_{\mathrm{f}}$ & $r$ & $D_{\mathrm{f}}$ & $r$ & $D_{\mathrm{f}}$ & $r$ \\
\hline $9.00 \pm 0.05$ & 2.20 & 0.3359 & 2.23 & 0.415 & 1.87 & 0.5074 & 2.04 & 0.5569 \\
\hline $7.00 \pm 0.05$ & 2.69 & 0.1428 & 2.56 & 0.2360 & 2.29 & 0.3727 & 2.27 & 0.4408 \\
\hline $5.00 \pm 0.05$ & 1.70 & 0.6089 & 1.97 & 0.5241 & 1.49 & 0.7309 & 1.72 & 0.6679 \\
\hline
\end{tabular}

a Allen empirical formula; ${ }^{\mathrm{b}}$ Logan empirical formula.

fractal dimension of flocs at initial $\mathrm{pH}=7.0$ is higher than that at initial $\mathrm{pH}=9.0$, and the least mass fractal dimension was found for flocs at initial $\mathrm{pH}=5.0$.

\subsection{Fractal dimensions based on floc images}

To demonstrate the effect of coagulant dosages on the fractal dimensions of flocs, Table 2 shows that the fractal dimensions and average diameters in the different topological spaces of PFC-HA flocs formed under different PFC dosages. For HA water with initial $\mathrm{pH}$ 9.0, all the fractal dimensions $D_{1}, D_{2}, D_{3}$ in the different topological spaces of flocs continue to decrease as the PFC dosage increases. $D_{2}$ based on the logarithm of areas (A) versus long diameter $\left(\log A\right.$ vs. $\left.\log d_{\mathrm{L}}\right)$ of floc images were higher than those based on the logarithm of areas versus perimeters $(P)(\log A$ vs. $\log P)$ of floc images. $D_{3}$ values were calculated by the logarithm of equivalent sphere volumes $\left(V_{\text {sphere }}\right)$ or equivalent ellipsoid volumes $\left(V_{\text {ellipsoid }}\right)$ versus long diameter of floc images. In general, equivalent ellipsoid volumes may give a more accurate estimation for volume. The average diameters fluctuated as the PFC dosage increases. For HA water with initial $\mathrm{pH} 7.0$, only the fractal dimensions $D_{2}$ based on $(\log A$ vs. $\left.\log d_{\mathrm{L}}\right)$ relation and $D_{3}$ based on $\left(\log V_{\text {sphere }}\right.$ vs. $\left.\log d_{\mathrm{L}}\right)$ relation continue to decrease as the $\mathrm{PFC}$ dosage increases, others fluctuate as the PFC dosage increases. For HA water with initial $\mathrm{pH}$ 5.0, all the fractal dimensions fluctuate as PFC dosage increases. In this work, the maximum arithmetic average diameter for flocs was about $2.31 \mathrm{~mm}$ in flocculated HA water at initial pH 9.0 at PFC dosage of $22.93 \mathrm{mg} / \mathrm{L}\left(\right.$ as $\mathrm{Fe}^{3+}$ ). However, the maximum arithmetic average diameter of about $2.45 \mathrm{~mm}$ for flocs in flocculated HA water at initial pH 7.0 at PFC dosage of $5.46 \mathrm{mg} / \mathrm{L}$ (as $\mathrm{Fe}^{3+}$ ) and at initial $\mathrm{pH} 5.0$, the maximum arithmetic average diameter was given at PFC dosage of $3.28 \mathrm{mg} / \mathrm{L}$ $\left(\right.$ as $\mathrm{Fe}^{3+}$ ) as $1.66 \mathrm{~mm}$.

\subsection{Pore surface fractal dimensions}

The pore surface fractal dimensions of dried PFC-HA flocs powder were calculated by fractal FHH equation or thermodynamic equation, and the corresponding linear regressions plots are shown in Fig. 4. Sample 1 was cryofixation-vacuum-freeze-dried PFC-HA flocs in flocculated HA water at initial $\mathrm{pH}$ 9.0, and sample 2 and sample 3 were flocs in flocculated HA water at initial pH 7.0 and 5.0, respectively. The calculated pore surface

Table 2 Fractal dimensions and average diameters in the different topological spaces of PFC-HA flocs

\begin{tabular}{|c|c|c|c|c|c|c|c|c|}
\hline \multirow[t]{2}{*}{ Initial pH } & \multirow{2}{*}{$\begin{array}{l}\mathrm{PFC}(\mathrm{mg} / \mathrm{L}, \\
\left.\text { as } \mathrm{Fe}^{3+}\right)\end{array}$} & \multicolumn{5}{|c|}{ Fractal dimensions in the different topological spaces } & \multicolumn{2}{|c|}{ Diameter $(\mathrm{mm})$} \\
\hline & & $\begin{array}{l}D_{1}(\log P \text { vs. } \\
\left.\log d_{\mathrm{L}}\right)\left(R^{2}\right)\end{array}$ & $\begin{array}{l}D_{2}(\log A \text { vs. } \\
\left.\log d_{\mathrm{L}}\right)\left(R^{2}\right)\end{array}$ & $\begin{array}{l}D_{2}(\log A \text { vs. } \\
\log P)\left(R^{2}\right)\end{array}$ & $\begin{array}{l}D_{3}\left(\log V_{\text {sphere }}\right. \\
\left.\text { vs. } \log d_{\mathrm{L}}\right)\left(R^{2}\right)\end{array}$ & $\begin{array}{l}D_{3}\left(\log V_{\text {ellipsoid }}\right. \\
\left.\text { vs. } \log d_{\mathrm{L}}\right)\left(R^{2}\right)\end{array}$ & Median & Arithmetic \\
\hline \multirow[t]{4}{*}{$9.00 \pm 0.05$} & 3.28 & $1.17(0.95)$ & $1.97(0.95)$ & $1.66(0.96)$ & $2.96(0.95)$ & $2.99(0.88)$ & 1.95 & 1.89 \\
\hline & 5.46 & $1.11(0.93)$ & $1.82(0.90)$ & $1.61(0.93)$ & $2.73(0.90)$ & $2.68(0.83)$ & 2.06 & 2.09 \\
\hline & 10.92 & $1.08(0.93)$ & $1.78(0.92)$ & $1.56(0.89)$ & $2.67(0.92)$ & $2.62(0.85)$ & 1.87 & 1.90 \\
\hline & 22.93 & $1.05(0.80)$ & $1.74(0.76)$ & $1.54(0.81)$ & $2.62(0.76)$ & $2.56(0.65)$ & 2.37 & 2.31 \\
\hline \multirow[t]{4}{*}{$7.00 \pm 0.05$} & 3.28 & $1.15(0.92)$ & $1.89(0.94)$ & $1.55(0.91)$ & $2.83(0.94)$ & $2.86(0.92)$ & 2.20 & 2.16 \\
\hline & 5.46 & $1.04(0.90)$ & $1.71(0.88)$ & $1.56(0.87)$ & $2.56(0.88)$ & $2.38(0.77)$ & 2.48 & 2.45 \\
\hline & 14.20 & $1.13(0.76)$ & $1.59(0.77)$ & $1.22(0.76)$ & $2.38(0.77)$ & $2.25(0.63)$ & 2.13 & 2.08 \\
\hline & 26.21 & $1.17(0.93)$ & $1.46(0.84)$ & $1.24(0.90)$ & $2.19(0.84)$ & $2.47(0.77)$ & 0.65 & 0.67 \\
\hline \multirow[t]{3}{*}{$5.00 \pm 0.05$} & 3.28 & $1.09(0.95)$ & $1.78(0.92)$ & $1.60(0.94)$ & $2.67(0.92)$ & $2.72(0.88)$ & 1.57 & 1.66 \\
\hline & 5.46 & $1.09(0.99)$ & $1.95(0.99)$ & $1.79(0.99)$ & $2.93(0.99)$ & $3.21(0.97)$ & 1.40 & 1.37 \\
\hline & 14.20 & $1.04(0.83)$ & $1.50(0.79)$ & $1.36(0.84)$ & $2.25(0.79)$ & $2.25(0.66)$ & 1.29 & 1.29 \\
\hline
\end{tabular}



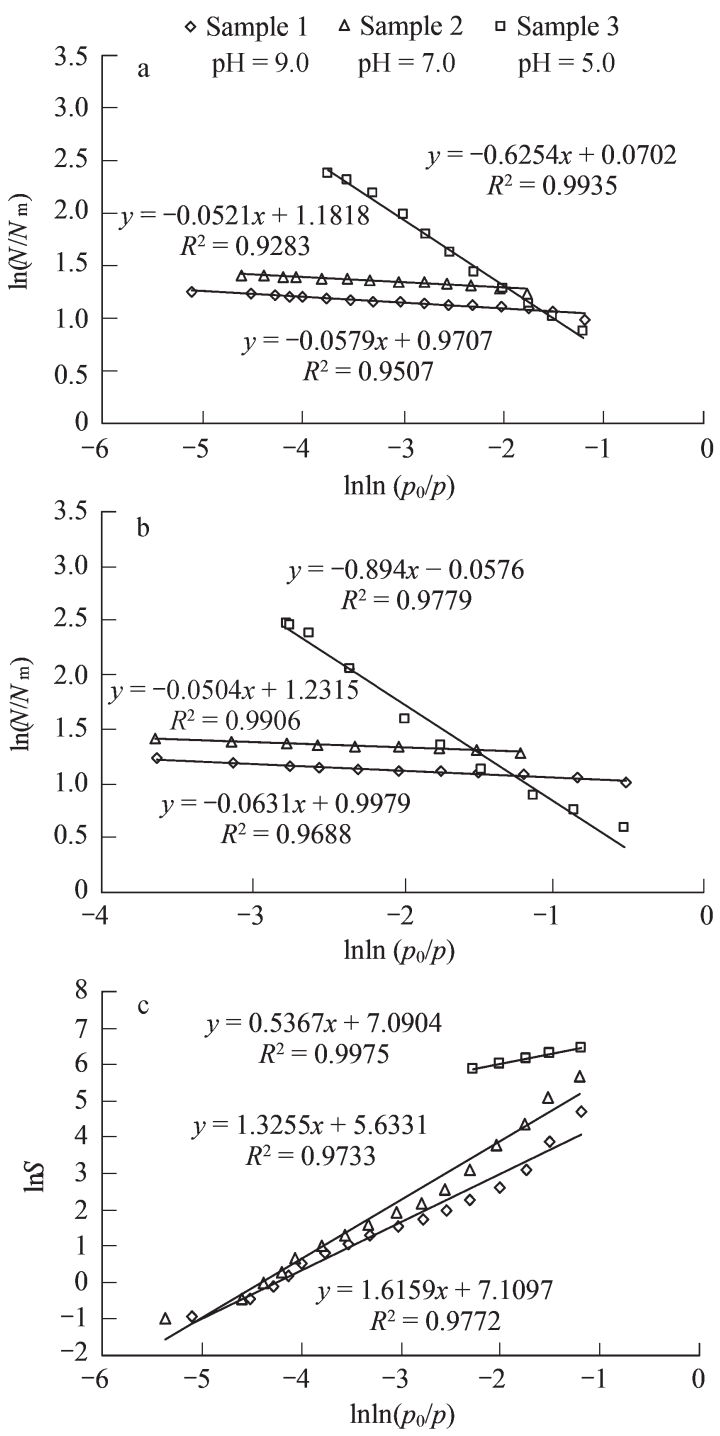

Fig. 4 Fractal analysis according to fractal FHH isotherm equation and thermodynamic model for cryofixation-vacuum-freeze-dried PFCHA flocs powder. (a) fractal FHH adsorption; (b) fractal FHH desorption; (c) thermodynamic equation. $N / N_{\mathrm{m}}$ : fractions of surface coverage; $P_{0} / P$ : ratio of saturation and equilibrium pressures of the adsorbate; $S$ : area of the "condensed adsorbate-vapor" equilibrium interface.

fractal dimensions of dried powder are given in Table 3. For HA water with initial $\mathrm{pH} 9.0$ and 7.0, the pore surface fractal dimensions at optimum PFC dosage were 2.9421 and 2.9479 respectively, based on fractal $\mathrm{FHH}$ equation. A little difference was shown when using the nitrogen adsorption data and desorption data. However, for HA water with initial $\mathrm{pH} 5.0$, the pore surface fractal dimension for these dried powder at optimum PFC dosage was 2.3746 based on fractal FHH equation with nitrogen adsorption data and 2.106 with nitrogen desorption data. When using thermodynamic equation, their pore surface fractal dimensions at optimum PFC dosage were different from that using fractal $\mathrm{FHH}$ equation and often show values higher than 3 (except at $\mathrm{pH}$ 5.0).

\section{Discussion}

In the floc settling-speed test, the geometric parameters of PFC-HA flocs at horizontal projected view and vertical projected view can be calculated using MiVnt software. The ratio between the average diameters (arithmetic average diameter or median diameter) for PFC-HA flocs at horizontal projected view and at vertical projected view were close to 0.85 (Table 4 ).

The settling rates and effective densities of flocs formed in different initial $\mathrm{pH}$ vs. equivalent diameters are shown in Fig. 5. Fig. 5a indicates that the settling rates of flocs formed in initial pH 5.0 were mostly less than the flocs with the same size formed under initial $\mathrm{pH} 7.0$ and 9.0. The ratio among the average settling rates for those flocs in HA water at initial pH 9.0, 7.0, and 5.0 was 1.11:1:0.50. In Fig. 5b, except for one floc, the effective densities of other flocs formed in initial $\mathrm{pH} 5.0$ were less than the flocs with the same size formed at $\mathrm{pH} 9.0$ and 7.0. The ratio among the average effective density for those flocs in HA water at initial $\mathrm{pH}$ of 9.0, 7.0, and 5.0 was 1.11:1:0.98 for Allen empirical formula, and 1.09:1:1.42 for Logan empirical formula.

The mass fractal dimensions $\left(D_{\mathrm{f}}\right)$ of PFC-HA flocs, being more than 2.0 , calculated by bi-logarithm relation of effective density-maximum diameter and Logan empirical formula at initial $\mathrm{pH} 7.0$ had $11 \%-13 \%$ greater than those at other initial $\mathrm{pH}$. Therefore, in comparison with the PFCHA flocs in HA water at initial $\mathrm{pH}$ of 5.0 and 9.0, the most compact flocs were formed in HA water at initial $\mathrm{pH}$ of 7.0, and the very smaller and looser flocs were formed in HA

Table 4 Average diameter (arithmetic average diameter/median diameter) and their ratio of PFC-HA flocs at different projected views

\begin{tabular}{llll}
\hline Initial $\mathrm{pH}$ & $\begin{array}{l}\text { Average } \\
d_{\mathrm{P}, \mathrm{H}}(\mathrm{mm})\end{array}$ & $\begin{array}{l}\text { Average } \\
d_{\mathrm{P}, \mathrm{V}}(\mathrm{mm})\end{array}$ & $\begin{array}{l}\text { Average } d_{\mathrm{P}, \mathrm{H}} / \\
\text { Average } d_{\mathrm{P}, \mathrm{V}}\end{array}$ \\
\hline $9.00 \pm 0.05$ & $1.8736 / 1.8486$ & $2.1784 / 2.1660$ & $0.8601 / 0.8535$ \\
$7.00 \pm 0.05$ & $1.7115 / 1.6661$ & $2.0209 / 1.9784$ & $0.8469 / 0.8421$ \\
$5.00 \pm 0.05$ & $0.9807 / 0.9518$ & $1.1476 / 1.1295$ & $0.8546 / 0.8427$
\end{tabular}

Average $d_{\mathrm{P}, \mathrm{H}}$ : average diameter for PFC-HA flocs at horizontal projected view; Average $d_{\mathrm{P}, \mathrm{V}}$ : average diameter for PFC-HA flocs at vertical projected view.

Table 3 Pore surface fractal dimensions of cryofixation-vacuum-freeze-dried PFC-HA flocs powder

\begin{tabular}{llll}
\hline Initial $\mathrm{pH}$ & FHH desorption equation & FHH desorption equation & Thermodynamic equation \\
\hline $9.00 \pm 0.05$ & $2.9421\left(R^{2}=0.9507\right)$ & $2.9369\left(R^{2}=0.9688\right)$ & $3.3255\left(R^{2}=0.9772\right)$ \\
& $(0.7375<x<0.9939)$ & $(0.552<x<0.9738)$ & $(0.7375<x<0.9939)$ \\
$7.00 \pm 0.05$ & $2.9479\left(R^{2}=0.9283\right)$ & $2.9496\left(R^{2}=0.9906\right)$ & $(0.7436<x<0.9742)$ \\
$5.00 \pm 0.05$ & $(0.8423<x<0.99)$ & $2.106\left(R^{2}=0.9779\right)$ & $(0.7392<x<0.9953)$ \\
& $2.3746\left(R^{2}=0.9935\right)$ & $(0.5547<x<0.9394)$ & $(0.7388<x<0.9028)$ \\
\hline
\end{tabular}

$R^{2}$ : linear definite coefficient; $x$ : ratio of $p$ and $p_{0}$. 

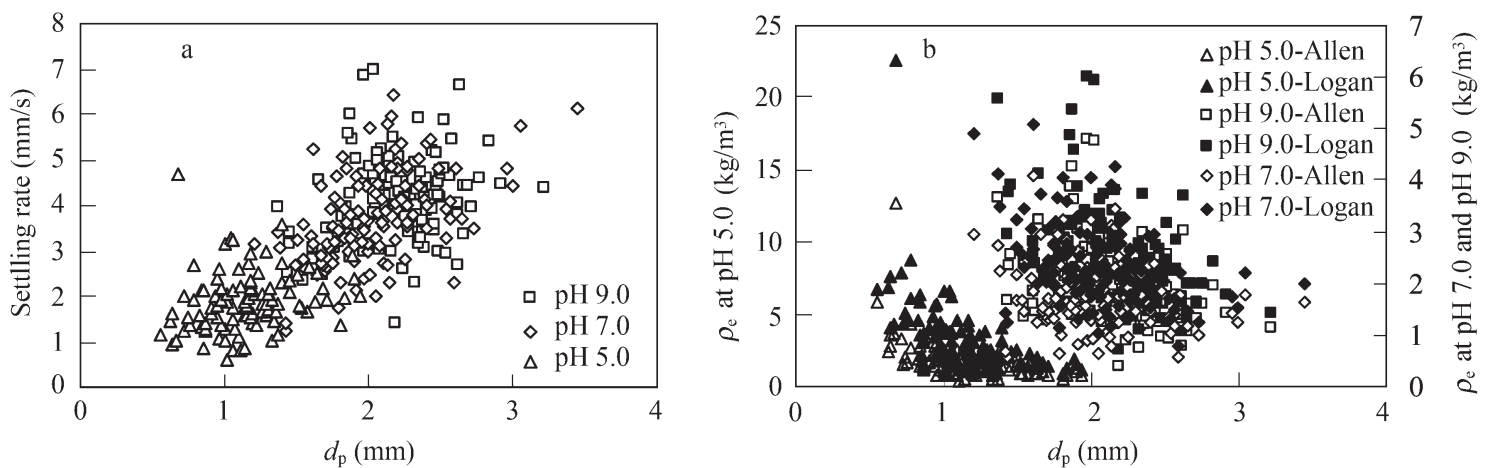

Fig. 5 Settling rate vs. equivalent diameter (a) and effective density vs. equivalent diameter (b).

water at initial $\mathrm{pH}$ of 5.0 and their $D_{\mathrm{f}}$ values were less than 2.0. At initial $\mathrm{pH}$ of 9.0, the $D_{\mathrm{f}}$ values of flocculated PFCHA flocs were close to 2.0 (Table 1). Combining the data of setting rates and effective densities of flocs, it revealed that mass fractal dimensions, effective density, and diameter of PFC-HA flocs could affect their setting rates, and both the highest value of mass fractal dimensions or effective density of PFC-HA flocs could not express the highest settling rate totally.

As shown in Table 2, the image analysis for those flocs indicates that after flocculating the HA water at initial $\mathrm{pH}$ greater than 7.0 with PFC flocculant, the fractal dimensions of $D_{2}\left(\log A\right.$ vs. $\left.\log d_{\mathrm{L}}\right)$ and $D_{3}\left(\log V_{\text {sphere }}\right.$ vs. $\log d_{\mathrm{L}}$ ) of PFC-HA flocs decreased with the increase in PFC dosages and flocs showed a gradually looser structure. At the optimum dosage of PFC, the $D_{2}\left(\log A\right.$ vs. $\left.\log d_{\mathrm{L}}\right)$ values of the flocs showed $14 \%-43 \%$ difference with their corresponding $D_{\mathrm{f}}$. The $D_{3}\left(\log V_{\text {sphere }}\right.$ vs. $\left.\log d_{\mathrm{L}}\right)$ or $D_{3}$ $\left(\log V_{\text {ellipsoid }}\right.$ vs. $\left.\log d_{\mathrm{L}}\right)$ values of the flocs showed $41 \%-$ $50 \%$, about $50 \%$ difference, respectively. Besides those, the $D_{2}\left(\log A\right.$ vs. $\left.\log d_{\mathrm{L}}\right)$ of the flocs formed under three initial HA solution $\mathrm{pH}$ showed a different tendency with the corresponding $D_{\mathrm{f}}$. These differences maybe caused by different floc images used for $D_{\mathrm{f}}$ and $D_{2}$ or $D_{3}$ calculation. The floc images for $D_{\mathrm{f}}$ calculation were recorded by CCD system in Fig. 1, and its magnification is in the range 6-9, but the flocs images for $D_{2}$ or $D_{3}$ calculation were recorded by CCD system in Fig. 2, and its magnification is in the range 26-31. The $D_{1}, D_{2}$, and $D_{3}$ values were calculated based on the floc images recorded by the CCD system in Fig. 1, and these flocs were also used in above

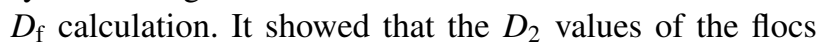
formed at three different initial HA solution $\mathrm{pH}$, based on the horizontal projected images with magnification of about 9 , had a same tendency with the corresponding $D_{\mathrm{f}}$.

The powder for above PFC-HA flocs were prepared by cryo-freeze-vacuum-dried method, and then were characterized by microstructure measurement. Their microstructure was investigated by $\mathrm{N}_{2}$ absorption-desorption method. It was observed that sample 3 (initial pH 5.0) has a hysteresis loop in the $\mathrm{N}_{2}$ absorption-desorption isotherm with a different shape from other two samples. The adsorption volume, Barret-Joyner-Halenda (BJH) cumulative absorption volume of pores, and $\mathrm{BJH}$ desorption average pore diameter of sample 3 were much higher than those of other samples, and those parameters of sample 2 (initial $\mathrm{pH}$ 7.0) were higher than sample 1 to certain extent. The pore-size distribution (PSD) of sample 3 shows that some marcopores exist in its surface. However, the BET specific surface area of these samples has a different trend from above surface geometrical parameters, and that of sample 2 was a little larger than that of sample 3 , and the sample 1 (initial $\mathrm{pH}$ 9.0) possessed the smallest. In general, the pore surface fractal dimensions $\left(D_{\mathrm{s}}\right)$ for sample 1 , sample 2 , and sample 3 showed that the former two samples had more ability for space-filling than the later one.

Although the geometrical irregularities and roughness of the surface are the essential reasons for the obtained $D_{\mathrm{s}}$, it is known that absorbed film volume and pore size distribution are used to define fractal in fractal $\mathrm{FHH}$ equation. The FHH type equation might be sensitive to the pore size distribution, therefore, pore size distribution can contribute significantly to the surface fractal dimension (El Shafei et al., 2004; Neimark and Unger, 1993; Sokołowska and Sokołowski, 1999). If the pore size distribution is fractal, the following Eq. (2) could be used to express these fractal relations.

$J(r)=b r^{2-D_{\mathrm{s}}}$

where, $J(r)$ is the pore size distribution function, $r$ is pore radius, and $D_{\mathrm{s}}$ is the surface fractal dimensions determined by pore size distribution. Therefore, the corresponding $D_{\mathrm{s}}$ for dried powder of PFC-HA flocs are listed in Table 6. Compare to the fractal dimensions for pore-size distribution, it can be shown that these pore surface fractal dimensions (Table 3) of PFC-HA flocs powder cannot totally represent the space-filling capability of irregular pore surface but mainly show the irregularity from the mesopore-size distribution and some marcoporesize distribution.

In addition, compared with the fractal FHH equation, the significant high pore surface $D_{\mathrm{s}}$ values for these samples were calculated through thermodynamic model, and most of them exceeded 3 (Table 3). Due to the hysteresis loop of a model in the $\mathrm{N}_{2}$ absorption-desorption isotherm for sample 3 (Zhao, 2005), the close values of its pore surface fractal dimension could be determined by both thermodynamic model and fractal FHH adsorption equation if the fractal scale is reduced. This result is given in Fig. 6, the former fractal scale is in the range $3.17-7.12 \mathrm{~nm}$, and the 
Table 5 Fractal dimensions of PFC-HA flocs in the onedimensional $\left(D_{1}\right)$ and twodimensional $\left(D_{2}\right)$ topological spaces

\begin{tabular}{|c|c|c|c|c|c|c|}
\hline \multirow[t]{2}{*}{ Initial $\mathrm{pH}$} & \multicolumn{3}{|c|}{ Vertical projected view } & \multicolumn{3}{|c|}{ Horizontal projected view } \\
\hline & $D_{1}\left(\log P\right.$ vs. $\left.\log d_{\mathrm{L}}\right)$ & $D_{2}\left(\log A\right.$ vs. $\left.\log d_{\mathrm{L}}\right)$ & $D_{2}(\log A$ vs. $\log P)$ & $\overline{D_{1}\left(\log P \text { vs. } \log d_{\mathrm{L}}\right)}$ & $D_{2}\left(\log A\right.$ vs. $\left.\log d_{\mathrm{L}}\right)$ & $\overline{D_{2}(\log A \text { vs. } \log P)}$ \\
\hline $9.00 \pm 0.05$ & $1.12\left(R^{2}=0.8418\right)$ & $1.41\left(R^{2}=0.8310\right)$ & $1.09\left(R^{2}=0.7427\right)$ & $1.04\left(R^{2}=0.8122\right)$ & $1.39\left(R^{2}=0.6354\right)$ & $1.17\left(R^{2}=0.5965\right)$ \\
\hline $7.00 \pm 0.05$ & $1.02\left(R^{2}=0.8676\right)$ & $1.52\left(R^{2}=0.7705\right)$ & $1.37\left(R^{2}=0.7457\right)$ & $1.02\left(R^{2}=0.8024\right)$ & $1.64\left(R^{2}=0.6779\right)$ & $1.37\left(R^{2}=0.6103\right)$ \\
\hline $5.00 \pm 0.05$ & $1.07\left(R^{2}=0.9271\right)$ & $1.66\left(R^{2}=0.8195\right)$ & $1.55\left(R^{2}=0.8831\right)$ & $1.07\left(R^{2}=0.8017\right)$ & $1.33\left(R^{2}=0.7616\right)$ & $1.07\left(R^{2}=0.7255\right)$ \\
\hline
\end{tabular}

Table 6 Pore surface fractal dimensions $\left(D_{\mathrm{s}}\right)$ of cryofixation-vacuum-freeze-dried PFC-HA flocs based on pore-size distribution

\begin{tabular}{lcccc}
\hline Initial $\mathrm{pH}$ & \multicolumn{2}{c}{ BJH adsorption pore distribution } & & \multicolumn{2}{c}{ BJH desorption pore distribution } \\
\cline { 2 - 4 } & $D_{\mathrm{s}}$ & Pore size $(\mathrm{nm})$ & $D_{\mathrm{s}}$ \\
\hline $9.00 \pm 0.05$ & $2.8839\left(R^{2}=0.9522\right)$ & $3.06-155.84$ & $2.9512\left(R^{2}=0.9128\right)$ \\
$7.00 \pm 0.05$ & $2.9985\left(R^{2}=0.9740\right)$ & $6.52-99.07$ & $3.1573\left(R^{2}=0.9332\right)$ \\
$5.00 \pm 0.05$ & $2.2652\left(R^{2}=0.8051\right)$ & $3.13-46.12$ & $2.1179\left(R^{2}=0.7397\right)$ \\
\hline
\end{tabular}

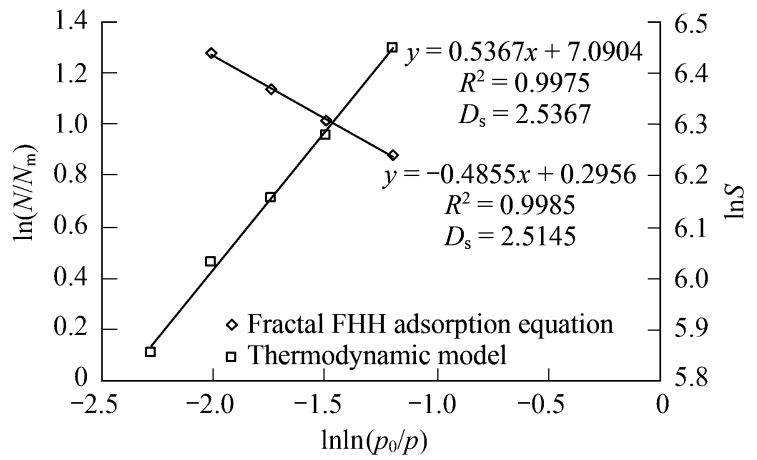

Fig. 6 Fractal analysis according to fractal FHH isotherm equation and thermodynamic model for sample 3 .

latter is in the range $2.15-4.84 \mathrm{~nm}$ (data not shown).

\section{Conclusions}

The PFC-HA floc effective density can be estimated by its settling-speed using Logan empirical formula and the mass fractal dimensions $D_{\mathrm{f}}$ of PFC-HA flocs, being more than 2.0 , calculated by bi-logarithm relation of effective density-maximum diameter. Logan empirical formula at initial $\mathrm{pH} 7.0$ had $11 \%$ or $13 \%$ greater than those at other initial $\mathrm{pH} 9.0$ or 5.0, which indicated that the most compact flocs were formed in HA water at initial $\mathrm{pH}$ 7.0. Both the highest value of $D_{\mathrm{f}}$ or effective density of PFC-HA flocs could not express their highest settling rate completely.

The image analysis for PFC-HA flocs indicated that after flocculating the $\mathrm{HA}$ water at initial $\mathrm{pH}$ greater than 7.0 with PFC flocculant, the fractal dimensions of $D_{2}(\log A$ vs. $\left.\log d_{\mathrm{L}}\right)$ and $D_{3}\left(\log V_{\text {sphere }}\right.$ vs. $\left.\log d_{\mathrm{L}}\right)$ of PFC-HA flocs decreased with the increase in PFC dosages, and PFCHA flocs showed a gradually looser structure. However, the fractal dimensions of PFC-HA flocs in flocculated water at initial $\mathrm{pH} 5.0$ fluctuated with the addition of PFC. At the optimum dosage of PFC, the $D_{2}(\log A$ vs. $\log d_{\mathrm{L}}$ ) values of the flocs show $14 \%-43 \%$ difference with their corresponding $D_{\mathrm{f}}$, even had different tendency as the change of initial $\mathrm{pH}$ values. But the $D_{2}$ values of the flocs formed under three initial HA solution $\mathrm{pH}$, calculated from the horizontal projected images with magnification of about 9 , had a same tendency with the corresponding $D_{\mathrm{f}}$ ones.
The pore-size distribution (PSD) of sample 3 (initial $\mathrm{pH}$ 5.0) shows that some marcopores exist in its surface, and BET specific surface area of these samples indicates that sample 1 (initial $\mathrm{pH}$ 9.0) possesses the smallest one among them. Based on fractal FHH adsorption and desorption equations, the pore surface fractal dimensions $D_{\mathrm{s}}$ for dried powders of sample 1 (initial $\mathrm{pH}$ 9.0) and sample 2 (initial $\mathrm{pH} 7.0$ ) were all close to 2.9421 , but $D_{\mathrm{s}}$ values of sample 3 (initial $\mathrm{pH}$ 5.0) were less than 2.3746. It appears that these pore surface fractal dimensions of PFC-HA flocs powder cannot fully represent the space-filling capability of irregular pore surface but mainly show the irregularity from the mesopore-size distribution and some marcoporesize distribution.

\section{Acknowledgments}

This work was supported by the National Natural Science Foundation of China (No. 20407004, 50578012, 50178009), the High-Tech Research and Development Program (863) of China (No. 2007AA06Z301), the Fok Ying Tung Education Foundation of National Education Ministry of China (No. 91078), the Beijing Municipal Commission of Education Project, Program for New Century Excellent Talents in University (No. NCET-06-0120), the Beijing Nova of Science and Technology, Beijing Key Subject (No. XK100220555).

\section{References}

Avnir D, Farin D, Pfeifer P, 1983. Chemistry in noninteger dimensions between two and three II: Fractal surfaces of adsorbents. Journal of Chemical Physics, 79: 3566-3571.

Avnir D, Farin D, Pfeifer P, 1985. Surface geometric irregularity of particulate materials: the fractal approach. Journal of Colloid and Interface Science, 103: 112-123.

Douglas J F, 1989. How does surface roughness affect polymersurface interactions. Macromolecules, 22: 3707-3716.

Edzwald J K, 1993. Coagulation in drinking water treatment: Particles, organics and coagulants. Water Science and Technology, 27(11): 21-35.

Edzwald J K, Tobiason J E, 1999. Enhanced coagulation: US requirements and a broader view. Water Science and Technology, 40(9): 63-70.

El Shafei G M S, Philip C A, Moussa N A, 2004. Fractal 
analysis of hydroxyapatite from nitrogen isotherms. Journal of Colloid and Interface Science, 277: 410-416.

Feder J, 1988. Fractals. New York: Plenum Press.

Fripiat J J, Gatineau L, Van Damme H, 1986. Multilayer physical adsorption on fractal surfaces. Langmuir, 2: 562-567

Gregory J, 1997. The density of particle aggregates. Water Science and Technology, 36(4): 1-13.

Jacangelo J G, DeMarco J, Owen D M, Randtke S J, 1995. Selected processes for removing NOM: an overview. Journal AWWA, 87(1): 64-77.

Jekel M R, 1986. The stabilization of dispersed mineral particles by adsorption of humic substance. Water Research, 20(12): $1543-1554$.

Jiang Q, Logan B E, 1991. Fractal dimensions determined from steady - state size distribution. Environmental Science and Technology, 25(12): 2031-2038.

Jin P K, Wang X C, 2001. Morphological characteristics of Al-humic floc and coagulation chemistry. Acta Scientiae Circumstantiae, 21(suppl): 23-29.

Li X Y, Logan B E, 2001. Permeability of fractal aggregates. Environmental Science and Technology, 35(14): 3373-3380.

Mandelbrot B B, 1982. The Fractal Geometry of Nature. San Francisco: Freeman.

Nègre $\mathrm{M}$, Leone $\mathrm{P}$, Trichet $\mathrm{J}$, Défarge $\mathrm{D}$, Boero $\mathrm{V}$, Gennari M, 2004. Characterization of model soil colloids by cryoscanning electron microscopy. Geoderma, 121(1-2): 1-16.

Neimark A V, Unger K K, 1993. Method of discrimination of surface fractality. Journal of Colloid and Interface Science, 158: 412-419.

Pfeifer P, Obert M, 1989. Fractals: basic concepts and terminology. In: The Fractal Aapproach to Heterogeneous Chemistry (Avnir D, ed.), New York: Wiley.

Pfeifer P, Obert M, Cole M W, 1989. Fractal BET and FHH theories of adsorption: a comparative study. In: Proceedings of the Royal Society of London. Series A, Mathematical and Physical Sciences. Vol. 423, No. 1864, Fractals in the Natural Sciences May 8, 1989. Princeton, New Jersey. 169188.

Russ J C, 1994. Fractal Surfaces. New York: Plenum Press.

Serra T, Logan B E, 1999. Collision frequencies of fractal bacterial aggregates with small particles in a sheared fluid. Environmental Science and Technology, 33(13): 22472251.

Sokołowska Z, Sokołowski S, 1999. Influence of humic acid on surface fractal dimension of kaolin: Analysis of mercuryporosimetry and water vapour adsorption data. Geoderma, 88: 233-249

Wang Y L, Lou M, Shi B Y, Wang D S, Liu J, Liao B H, 2006a. Removing humic acid in water by the integrated process of micro-eddy flocculation (MEF)-counter current dissolved air flotation (CCDAF)-nanofiltration (NF), PFC as flocculant. Acta Scientiae Circumstantiae, 26(5): 791797.

Wang Y L, Shi B Y, Du B Y, Liu J, 2006b. Surface and pore characterization of cryofixation-vacuum-freeze-dried polyferric chloride-humic acid (PFC-HA) flocs by fractal method. Acta Scientiae Circumstantiae, 26(9): 1474-1483.

Wang Y L, Du B Y, Liu J, Lu J, Shi B Y, Tang H X, 2007. Surface analysis of cryofixation-vacuum-freeze-dried polyaluminum chloride-humic acid (PACl-HA) flocs. Journal of Colloid and Interface Science, 316: 457-466.

Wang X C, Tambo N, 2000. A study on the morphology and density of flocs I. The fractal structure of floc. Acta Scientiae Circumstantiae, 20(3): 257-262.

Yan X S, Fan J C, 1999. Water Supply Engineering. Beijing: Chinese construction industry press.

Zhao Z G, 2005. Principals for Application of Adsorption. Beijing: Chemical industry press. 